\title{
O QUE APRENDEMOS DAQUILO QUE NOS É ENSINADO
}

¿QUÉ APRENDEMOS DAQUILO QUE NOS ES ENSEÑADO?

WHAT WE LEARN FROM WHAT IT IS TAUGHT TO US

\author{
Andreza Olivieri Lopes CARMIGNOLLI ${ }^{1}$ \\ Luci Regina MUZZETI ${ }^{2}$
}

RESUMO: Este texto apresenta um relato de pesquisa sobre o componente curricular de Ciências Físicas e Biológicas, utilizado para analisar o processo de ensino por meio da experiência de ensinar e aprender. As leis $N^{\circ} 4024 / 61$, No 5692/71 e No 9394/96 serão citadas para demonstrar a evolução no ensino de ciências. Entretanto, nosso objetivo é mostrar que a aprendizagem só se torna significativa quando a experiência faz sentido para o aprendiz e o ajuda a construir o conhecimento.

PALAVRAS-CHAVE: Ensino de ciências. Experiência. Aprendizagem. Conhecimento.

RESUMEN: Este texto presenta un relato de investigación sobre el componente curricular de Ciencias Físicas y Biológicas, utilizado para analizar el proceso de enseñanza a través de la experiencia de enseñar y aprender. Las leyes $N^{o} 4024 / 61, N^{o}$ 5692/71 y $N^{\circ}$ 9394/96 serán citadas para demostrar la evolución en la enseñanza de las ciencias. Sin embargo, nuestro objetivo es mostrar que el aprendizaje sólo se vuelve significativo cuando la experiencia tiene sentido para el aprendiz y le ayuda a construir el conocimiento.

PALAVRAS-CLAVE: Enseñanza de las ciencias. Experiencia. Aprendizaje. Conocimiento.

ABSTRACT: This text presents a research report about the curricular component of Physical and Biological Sciences, used to analyze the teaching process through the experience of teaching and learning. The Laws No. 4024/61, No. 5692/71 and No. 9394/96 will be cited to demonstrate the evolution in the science teaching. However, our goal is to show that learning becomes meaningful only when experience makes sense to the learner and helps him/her to build knowledge.

KEYWORDS: Science education. Experience. Learning. Knowledge.

\footnotetext{
${ }^{1}$ Universidade Estadual Paulista (Unesp), Araraquara - SP - Brasil. Mestranda do Programa de Pósgraduação em Educação Escolar, Faculdade de Ciências e Letras de Araraquara. E-mail: carmignolli@hotmail.com

${ }^{2}$ Universidade Estadual Paulista (Unesp), Araraquara - SP - Brasil. Docente do Programa de Pósgraduação em Educação Escolar, Faculdade de Ciências e Letras de Araraquara. E-mail: lucirm@fclar.unesp.br
} 


\section{Introdução}

O cenário educacional atual destaca a importância do ensino integral dos educandos nas diferentes áreas do conhecimento, conforme previsto nas expectativas de aprendizagem do Currículo do Estado de São Paulo.

É na escola que ocorrem diferentes aprendizagens por meio da interação e internalização de várias crenças e vários resultados, proporcionando ao aluno a aquisição de novos conhecimentos, através de experiências e rodas de conversa.

Neste relato de pesquisa, utilizarei o componente curricular de Ciências Físicas e Biológicas como análise do processo de ensino por meio da experiência.

O ensino de Ciências tem passado por mudanças que vão desde alterações na legislação educacional, formação de professores, concepções sobre o processo de ensino-aprendizagem até a elaboração de materiais didáticos.

A partir da década de 1960, as principais alterações e os aprimoramentos legais educacionais estão pautados na Lei de Diretrizes e Bases da Educação Nacional (LDBEN) e foram marcados pelas leis: Lei $N^{\circ} 4024 / 61$, Lei $N^{o} 5692 / 71$ e Lei $N^{\circ}$ 9394/96, numa perspectiva evolutiva.

A seguir, apresento alguns pontos fundamentais em relação ao ensino de Ciências e ao período histórico do país.

\section{Lei $N^{\circ} 4024 / 61$}

O conhecimento científico era neutro e inquestionável; apesar do cenário educacional estar passando por um momento de renovação, o ensino pautava-se na memorização de questionários e avaliações e o professor tinha o papel de transmitir os conhecimentos acumulados pela humanidade.

\section{Lei $\mathbf{N}^{\circ} 5692 / 71$}

Na década de 1970, o ensino de Ciências passou a ser denominado como Ciências e Programas de Saúde, inserido na grade curricular de todas as séries do $1^{\circ}$ grau.

Nesse período, o ensino seguia o processo de industrialização e as propostas de 
ensino tinham como finalidade acompanhar o desenvolvimento tecnológico do período.

Sendo assim, o ensino de Ciências tem como objetivo levar o aluno a identificar problemas, com base em observações, para chegar a possíveis soluções por suas próprias conclusões.

\section{Lei $\mathbf{N}^{\circ}$ 9394/96}

A Lei $N^{o}$ 9394/96 traz como obrigatoriedade a abrangência do conhecimento do mundo físico e natural. O ensino de Ciências tem o objetivo de levar o aluno a compreender as mudanças do ambiente e a atuar como cidadão participativo. $\mathrm{O}$ professor, por sua vez, tem o papel de conduzir a aprendizagem do aluno pautando-se em concepções construtivistas.

Dessa forma, a história do ensino de Ciências mostra que o levantamento das mudanças educacionais está relacionado às condições sociais, políticas e econômicas do país que contribuíram para a qualidade da educação brasileira através da formação de professores, participação das universidades na produção de material didático e mudança dos métodos de ensino. Mas isso não basta para que o conhecimento seja adquirido pelo aluno. $\mathrm{O}$ ensino precisa ter sentido e significado para ser transformado em conhecimento.

\section{A importância da experiência para a aprendizagem}

Uma aprendizagem significativa é constituída por experiências. Para Larrosa (2002, p. 21), "a experiência é o que nos passa, o que nos acontece, o que nos toca", sendo definida como a capacidade de formação ou de transformação; mas é preciso deixar claro que experiência não significa bagagem de informação. Portanto, informação não é experiência. A informação tem por finalidade checar nossos conhecimentos sobre um determinado assunto.

Dessa maneira, a opinião teria um caráter subjetivo e a informação, um caráter objetivo dentro da aprendizagem significativa. "Como se o conhecimento se desse sob a forma de informação, e como se aprender não fosse outra coisa que não adquirir e processar informação" (LARROSA, 2002, p. 22) 
O autor julga necessário, no processo de conhecimento, a separação entre experiência e saber de experiência, uma vez que este implica em mudanças atitudinais de dentro para fora, a partir do aprendizado adquirido, para que a aprendizagem não signifique apenas o processamento de informações e o conhecimento esteja atrelado à informação.

A experiência é o produto da reflexão do indivíduo consigo mesmo, por meio de gestos, análise das diferentes situações e até aprendizagens, em que o sujeito da experiência será definido na participação de cada etapa. "[...] fazer uma experiência com algo significa que algo nos acontece, nos alcança; que se apodera de nós, que nos tomba e nos transforma" (HEIDEGGER, 1987, p. 143). O saber da experiência surge do conhecimento com a vida humana, é um saber subjetivo.

Atualmente, podemos observar que os projetos de ensino são recursos didáticos utilizados como ferramenta para auxiliar o processo de aprendizagem dos diferentes componentes curriculares. É um facilitador na construção do conhecimento por partirem de situações concretas do cotidiano dos alunos.

No contexto escolar, os projetos têm como finalidade proporcionar a construção da aprendizagem por meio da participação ativa dos professores e alunos num processo mútuo de troca de informações e experiências, sendo que ambos estão inseridos no processo de aquisição do conhecimento de maneira significativa e prazerosa.

Durante as participações de professores e alunos nas atividades desenvolvidas é que se constroem as motivações intrínsecas, uma das características das situações de ensino-aprendizagem de todos os envolvidos nesse processo.

O processo de aprender pressupõe uma mobilização cognitiva, o que constitui um desafio para o aluno, algo que ainda não construiu e que, de acordo com suas possibilidades, irá adquirir na aquisição de novos conhecimentos.

$\mathrm{Na}$ construção do conhecimento, um dos aspectos importantes para o desenvolvimento dos alunos é a interação, pois, é por meio das relações sociais que os sujeitos aprendem e desenvolvem suas funções psicológicas superiores, que são típicas do ser humano, e podem ser observadas no controle do comportamento, no planejamento de ações futuras e na possibilidade de imaginar situações nunca antes vividas.

A prática pedagógica por meio de projetos envolve alunos e professores no processo de ensino-aprendizagem, através dos recursos disponíveis e das finalidades didáticas estabelecidas nesse contexto, cabendo à escola preparar o aluno para o 
convívio atuante na sociedade por meio das relações estabelecidas dentro desse espaço.

\section{Considerações finais}

Oportunizar experiências como essas é importante para o processo de ensinoaprendizagem no sentido de enriquecer a base de conhecimento que o educando traz de sua realidade. Nesse processo, a troca de experiência é de extrema importância tanto para professores quanto para alunos: parte-se daquilo que é conhecido para ir além; difundir conceitos, experimentar e comprovar, ou não, hipóteses.

A partir do desenvolvimento de projetos em instituições escolares, estamos propiciando e, ao mesmo tempo, oportunizando o enriquecimento do arcabouço teórico que é de domínio do aluno e aprimorando conhecimentos angariados pelo professor, tendo em vista seu aperfeiçoamento profissional e a busca de novas informações mediante o avanço científico.

Desse modo, o uso de projetos em sala constitui-se como um importante meio ou estratégia de possibilitar aos educandos a aprendizagem de vários e múltiplos conteúdos, os quais de forma variada são aprendidos de modo significativo, a partir de situações cotidianas.

Mas será que podemos afirmar que o uso de projetos nas instituições escolares ou outras metodologias de ensino garantem um aprendizado, ou melhor, o que é ensinar e o que é aprender?

Para Kohan (2003), talvez ensinar se relacione a propiciar marcas que podem ser seguidas por outros, em que também se aprende quando ensina.

O processo de ensino pressupõe que a comunicação entre professor e aluno deve ser pautada em um mesmo objetivo, estando em jogo a vontade de quem ensina e a vontade de quem aprende. Quando essas vontades coincidem, é produzido o embrutecimento, pois há uma subordinação da inteligência a algo externo, ou seja, a outra inteligência. Explicar algo a alguém é subestimar sua capacidade intelectual, afirmando que não há capacidade de entendimento. Isso fica claro nas aulas de matemática, quando o professor não explora as diferentes maneiras utilizadas pelos alunos para a resolução de um problema, utilizando apenas a maneira que considera correta na correção do exercício/problema.

Já quando a inteligência não obedece só a si mesma ocorre a emancipação. $\mathrm{O}$ 
processo de emancipação deve começar pelo próprio mestre, partindo do princípio de que todos os seres humanos têm a mesma capacidade de pensamento e ninguém é melhor do que ninguém.

Então, aprender é apropriar-se dos conhecimentos transmitidos com nossos próprios ideais, nossa inteligência, sem copiar o que está pronto. E ensinar é oferecer caminhos, maneiras de aprender por meio de experiências pessoais.

\section{REFERÊNCIAS}

BRASIL. Lei 4.024, de 20 de dezembro de 1961. Fixa as Diretrizes e Bases da Educação Nacional. Brasília, DF: 1961.

BRASIL. Lei 5.692, de 11 de agosto de 1971. Fixa Diretrizes e Bases para o ensino de $1^{\circ}$ e $2^{\circ}$ graus, e dá outras providências. Brasília, DF: 1971.

BRASIL. Lei 9.394, de 20 de dezembro de 1996. Fixa Diretrizes e Bases da Educação Nacional. Brasília, DF: 1996.

LEITE, Lúcia Helena Alvarez. Pedagogia de projetos e projetos de trabalho. Presença Pedagógica, v. 73, p. 62-69, 2007.

HEIDEGGER, Martin. La esencia del habla. In: HEIDEGGER, Martin. De camino Al habla. Barcelona: Educaciones Del Serbal, 1987.

KOHAN, Walter Omar. Infância de um ensinar e de um aprender (J. Rancière). In: KOHAN, Walter Omar. Infância. Entre Educação e Filosofia. Belo Horizonte: Autêntica, 2003. p. 181-205.

LARROSA, Jorge. Notas sobre a experiência e o saber de experiência. Tradução de João Wanderley Geraldi. Revista Brasileira de Educação, n. 19, p. 20-28, jan./abr, 2002.

SÃO PAUlO. Secretaria de Educação. Currículo do Estado de São Paulo: Ciências da Natureza e suas tecnologias. São Paulo, 2010.

SÃO PAULO. Governo do Estado. Secretaria da Educação. Coordenadoria de Gestão da Educação Básica. Orientações curriculares do estado de São Paulo: ciências naturais e ciências humanas. São Paulo: CGEB/SEE, 2013.

SÃO PAULO. Secretaria da Educação. Proposta Curricular para o ensino

fundamental (Ciclo II) e ensino médio: documento de apresentação. São Paulo, 2008. 


\section{Como referenciar este artigo}

CARMIGNOLLI, Andreza Olivieri Lopes.; MUZZETI, Luci Regina. O que aprendemos daquilo que nos é ensinado. Temas em Educ. e Saúde, Araraquara, v.13, n.1, p. 179-185, jan./jun. 2017. DOI <https://doi.org/10.26673/rtes.v13.n1.janjun2017.9996>. ISSN: 1517-7947.

Submetido em: 09/05/2017

Aprovado em: 20/08/2017 